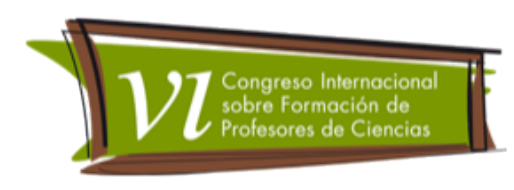

\title{
Proyecto de aula \\ Construcción de la alfabetización científica a partir del trabajo con cuestiones socio científicas (CSC). Problemática de la contaminación del rio Bogotá
}

Molano Andrés Mauricio 1

Categoría 2. Trabajo de investigación (en proceso)

\section{Resumen}

La implementación de las cuestiones socio científicas (csc) en el aula permiten involucrar al estudiante con temáticas de su contexto generando interés y un desarrollo adecuado de diversas temáticas curriculares en ciencias. El presente artículo muestra la metodología aplicada en estudiantes de educación básica secundaria en donde se implementó el trabajo con csc para el desarrollo de la alfabetización científica estructurando una secuencia didáctica a partir del tratamiento de aguas negras. La CSC trabajada es el tratamiento de aguas negras de una vertiente del rio Bogotá ubicado aledaño al colegio Alcalá ubicado al sur de Bogotá.

\section{Palabras clave}

CSC, alfabetización científica, secuencia didáctica, enseñanza de las ciencias.

\section{Introducción}

La educación científica debe ser productiva y generar educandos participes en sus procesos de enseñanza y aprendizaje, además este aprendizaje se debe reflejar mediante la capacidad de intervenir en diferentes problemáticas de tipo social y cultural de manera crítica y consiente, generando aportes que permitan la construcción de nuevas alternativas a las diferentes situaciones que se plantean en un contexto científico, social y tecnológico (relaciones CTS).

Partiendo de lo anterior se evidencia La importancia de modificar las estrategias de enseñanza y aprendizaje en el aula para que estos procesos participativos se generen

${ }^{1}$ Candidato a magíster Universidad Pedagógica Nacional. 
Revista Tecné, Episteme y Didaxis: TED. Año 2014, Número Extraordinario. ISSN Impreso: 0121-3814, ISSN web: 2323-0126

Memorias, Sexto Congreso Internacional sobre Formación de Profesores de Ciencias. 08 al 10 de octubre de 2014, Bogotá

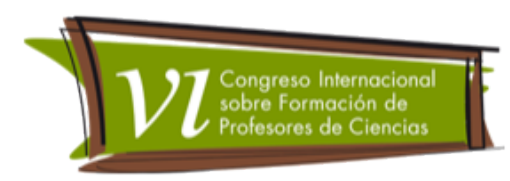

desde la educación básica y media y se logre alcanzar el proceso de desarrollo de alfabetización científica que permita la construcción de una sociedad más participativa involucrada en aspectos de tipo científico y tecnológico.

La propuesta presentada se basa en la aplicación de cuestiones socio científicas en la enseñanza de la química en educación básica y media a partir de procesos de construcción de aprendizaje (alfabetización científica), en los que la aplicación de un proyecto de aula creada para dicho objetivo permitirá involucrar a los estudiantes en un contexto conocido facilitando el interés y por ende la participación en el desarrollo de la propuesta.

La temática abordar se plantea mediante una actividad inicial en el desarrollo del proyecto en la que se establece la estrategia de cartografía ambiental para poder identificar las percepciones y los intereses de los estudiantes de grado sexto del colegio Alcalá ubicado en villa del rio (sur de Bogotá). En donde se pudo determinar que el impacto generado por la contaminación que el rio genera es visto como uno de los principales problemas del sector.

La temática es conocida por los estudiantes y permite partir de ella para tratar diferentes temáticas relacionadas en el área de ciencias naturales en el plan de estudios de dicha institución. Este proyecto de aula busca generar la inclusión de las cuestiones socio científicas (CSC) en las clases de ciencias fomentando la alfabetización científica,

Involucrando los docentes en el proceso de enseñanza Mediante estrategias didácticas diferentes a las trabajadas en un modelo tradicional en busca de la formación de estudiantes activos en sus procesos educativos y participativos en la comunidad. Se pretende mediante esta propuesta Evidenciar las repercusiones que generan las cuestiones socio científicas aplicadas en el aula como modelo de enseñanza mediante el cual se formen estudiantes críticos y participativos en relaciones CTSA.

Al Establecer parámetros que permitan modificar las prácticas docentes en la asignatura de química podemos fomentar la alfabetización científica como proceso de desarrollo del pensamiento involucrando a los estudiantes con las problemáticas de su entorno y convirtiéndolos en actores en busca de soluciones a dichas problemáticas. Conocer el funcionamiento y los impactos sociales, económicos, políticos y culturales que causa la implicación de una parte de la contaminación del rio Bogotá. 
Revista Tecné, Episteme y Didaxis: TED. Año 2014, Número Extraordinario. ISSN Impreso: 0121-3814, ISSN web: 2323-0126

Memorias, Sexto Congreso Internacional sobre Formación de Profesores de Ciencias. 08 al 10 de octubre de 2014, Bogotá

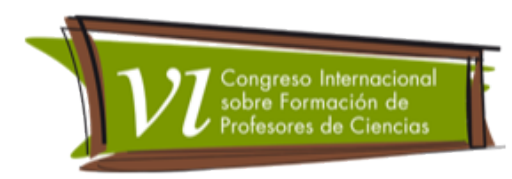

¿Porqué trabajar con CSC?..

La búsqueda en la calidad de educación debe ser uno de los aspectos mas trabajados por los docentes los cuales deben estar comprometidos con el desarrollo integral en el proceso de enseñanza y aprendizaje, además de convertirse en constantes investigadores en el aula permitiendo engrosar el entramado conceptual que rodea esta práctica profesional. No se puede omitir el aspecto socioeconómico y cultural que involucra a los estudiantes en unas expectativas y una posición referente al aprendizaje, el cual es un factor determinante para el desarrollo y la construcción de procesos los cuales son los que garantizan un adecuado desarrollo de competencias en el aula.

Se debe tener en cuenta que hoy en día la escuela no es la principal fuente de información de los estudiantes, gracias a los diferentes avances tecnológicos Y Los medios de comunicación la información es de dominio publico ya no es centralizada, Sino que por el contario se construyen conocimientos a partir de diferentes puntos de vista que fácilmente se pueden divulgar y compartir entre pares o entre un conjunto de personas interesadas en la construcción de algún tipo de conocimiento. Este factor es fácilmente aprovechable al trabajar a partir del planteamiento de cuestiones sociocientíficas CSC. En la enseñanza y el aprendizaje de las ciencias.

La importancia de la investigación se ve reflejada en la aplicación de nuevas estrategias de aula para poder fomentar el pensamiento crítico en los estudiantes contribuyendo a ampliar el sistema científico del país y el desarrollo directo del mismo. De ahí la importancia de estimular el aprendizaje científico desde temprana edad. No se trata de que en la escuela se fabriquen nuevos científicos como tal, sino seres pensantes, reflexivos y críticos, que basen sus ideas en hechos, hagan inferencias a partir de estos, sean creativos y tomen decisiones en consecuencia.

¿Qué hace la problemática del rio Bogotá una CSC?

1. Se han encontrado distintas publicaciones en artículos de prensa sobre el problema de la manipulación de alimentos.

2. Permite en los estudiantes de grado sexto explicar el funcionamiento de los conservantes químicos y desarrollar los estándares del MEN

3. Es una temática multidisciplinar que permite integrar varias áreas

4. La noticia circula en los Medios de comunicación.

5. El tema de controversia tiene implicaciones locales y globales,

6. Promueve actitudes responsables frente al consumo de alimentos 
Revista Tecné, Episteme y Didaxis: TED. Año 2014, Número Extraordinario. ISSN Impreso: 0121-3814, ISSN web: 2323-0126

Memorias, Sexto Congreso Internacional sobre Formación de Profesores de Ciencias. 08 al 10 de octubre de 2014, Bogotá

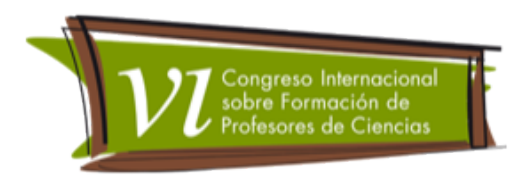

\section{Marco teórico}

Acerca de las csc en la alfabetización:

La ciencia es metodológicamente crítica, pero para que se pueda considerar socialmente como pensamiento crítico, tiene que abordar cuestiones con implicaciones sociales y/o cuestionar el discurso o intereses de las clases y poderes dominantes. Esto suele producir, conflictos o persecuciones de los científicos involucrados. Solves (2013). Por otro lado, la realización de propuestas de intervención desde las CSC favorecen el pensamiento crítico y la argumentación (Zenteno-Mendoza \& Garritz, (2010), Beltrán, M. (2010), Martínez, et al. (2009), Solbes, (2013) por nombrar algunas), lo cual es primordial para el desarrollo de procesos de alfabetización científica en los estudiantes al mismo tiempo que los motivan a aproximarse al conocimiento científico para la construcción de una explicación sobre la actividad científica y sus productos más acorde con lo actual, comprendiendo su potencial, sus limitaciones e integrando un componente interdisciplinar de estudio.

Se quiere generar una solución a la problemática que hoy en día se presenta en donde se evidencia una clara desmotivación hacia el aprendizaje específicamente en ciencias como la química (Hopkins 2008). Para ello Se pretende obtener estudiantes con mejor rendimiento en las áreas de ciencia específicamente química a partir del trabajo científico involucrado desde grado sexto, creando una nueva cultura científica que permita que los estudiantes piensen y observen el mundo como un gran laboratorio de aprendizaje y descubrimiento.

El sentido de proponer este tipo de controversias es fomentar la alfabetización científica, en los estudiantes, cuestionando las distintas interacciones, causas, efectos y motivos de su realidad inmediata y el mundo que los rodea, para el desarrollo de juicios autónomos sobre ese entorno y participar en su cambio.

En relación a lo anterior existen numerosas investigaciones en la didáctica de las ciencias en el transcurso de los últimos años que reflejan de modo insistente una intranquilidad por las diversas dificultades que se presentan en los procesos de aprendizaje en la enseñanza de las ciencias

Vislumbrándose una formación de estudiantes mediante contenidos descontextualizados, sin la integración de valores, ni la implementación de conocimientos de frontera, sin evidenciar las interacciones entre la ciencia y la tecnología con la 
Revista Tecné, Episteme y Didaxis: TED. Año 2014, Número Extraordinario. ISSN Impreso: 0121-3814, ISSN web: 2323-0126

Memorias, Sexto Congreso Internacional sobre Formación de Profesores de Ciencias. 08 al 10 de octubre de 2014, Bogotá

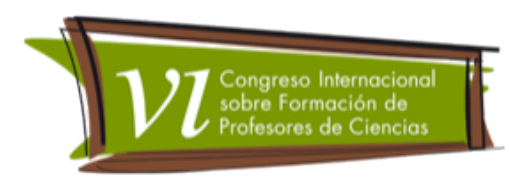

sociedad y el ambiente y, el poco desarrollo de habilidades para criticar, reflexionar, negociar y participar en la trasformación de su medio.

Por lo cual, este tipo de propuestas sugieren un cambio en los modos de ver el currículo e introducir el enfoque CTSA y una de sus directrices las CSC que tienen en cuenta este tipo de falencias presentes en la educación.

La alfabetización científica debe ser concebida, como un proceso de "investigación orientada" que, superando el reduccionismo conceptual permita a los alumnos participar en la aventura científica de enfrentarse a problemas relevantes y (re)construir los conocimientos científicos, que habitualmente la enseñanza transmite ya elaborados, lo que favorece el aprendizaje mas eficiente y significativo. (Sabariego del castillo \& Manjarrez, 2006).

Una persona alfabetizada científicamente debe ser capaz de:

- Utilizar conceptos científicos e integrar valores y saberes para adoptar decisiones responsables en la vida cotidiana

- Comprender la relación que existe entre la sociedad la ciencia y la tecnología

- Reconocer los limites y utilidad de la ciencia en el bienestar humano

- Conocer las principales conceptos hipótesis y teorías científicas y ser capaz de aplicarlos

- Comprender la importancia de la investigación para la producción de saberes científicos y diferenciarlos de las opiniones personales

- reconocer el origen de la ciencia y comprender que el saber científico es provisorio y sujeto al cambio Fourez (1999).

En busca de lo planteado por Fourez se establece una propuesta de aula que tendrá como metodología una secuencia didáctica que permita fomentar y evidenciar la contribución de la CSC en la alfabetización científica.

Tratamiento de aguas:

A partir de la temática de tratamiento de aguas se abarcan diferentes contenidos en ciencias naturales mediante una secuencia didáctica diseñada para dicho objetivo que permite evidenciar el fomento y la construcción de la alfabetización científica mediante la aplicación de CSC en el aula.es necesario aclarar ciertos términos que serán trabajados en gran medida en el desarrollo de la investigación como: 
Revista Tecné, Episteme y Didaxis: TED. Año 2014, Número Extraordinario. ISSN Impreso: 0121-3814, ISSN web: 2323-0126

Memorias, Sexto Congreso Internacional sobre Formación de Profesores de Ciencias. 08 al 10 de octubre de 2014, Bogotá

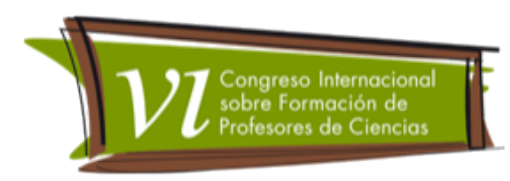

Agua residuales; Se puede definir el agua residual como la combinación de los residuos líquidos procedentes de residencias, instituciones públicas y establecimientos industriales y comerciales a los que pueden agregarse, eventualmente, aguas subterráneas, superficiales y pluviales.

En la medida en que se vaya presentando acumulación y estancamiento del agua residual pueden generarse gases de mal olor debido a la descomposición orgánica que ésta posee; además es importante anotar que en el agua residual hay existencia de numerosos microrganismos patógenos y causantes de enfermedades que habitan en el aparato intestinal humano $o$ que pueden estar en ciertos residuos industriales. Pero no todo es negativo, las aguas residuales contienen nutrientes que en gran parte ayudan al crecimiento de plantas acuáticas.

\section{Tipos de tratamientos}

Aquellos métodos de tratamiento en los que predominan los fenómenos físicos se conocen como operaciones unitarias, mientras que aquellos métodos en los que la eliminación de los contaminantes se realiza con base en procesos químicos o biológicos se conocen como procesos unitarios.

\section{Tratamientos preliminares}

Se hacen como antecedentes a los tratamientos primarios, secundarios, o terciarios, pues las aguas residuales pueden venir con desechos muy grandes y voluminosos que no pueden llegar a las plantas de tratamiento y sirven de igual manera para aumentar la efectividad de estos procesos. Para estos procesos son utilizados las rejillas, los tamices y los microfiltros.

\section{Tratamientos primarios}

En este tipo de tratamiento lo que se busca es remover los materiales que son posibles de sedimentar, usando tratamiento físicos o físico-químicos. En algunos casos dejando, simplemente, las aguas residuales un tiempo en grandes tanques o, en el caso de los tratamientos primarios mejorados, añadiendo al agua contenida en estos grandes tanques, sustancias químicas quelantes (La precipitación química o coagulación es un proceso por el cual se agregan sustancias químicas para que así se de una coagulación de los desechos y poder retirar así los sólidos) que hacen más rápida y eficaz la sedimentación. También se incluyen en estos tratamientos la neutralización del $\mathrm{pH}$ y la eliminación de contaminantes volátiles como el amoniaco (desorción). Las 
Revista Tecné, Episteme y Didaxis: TED. Año 2014, Número Extraordinario. ISSN Impreso: 0121-3814, ISSN web: 2323-0126

Memorias, Sexto Congreso Internacional sobre Formación de Profesores de Ciencias. 08 al 10 de octubre de 2014, Bogotá

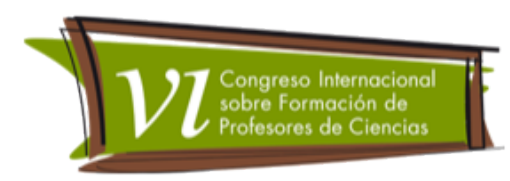

operaciones que incluye son el desaceitado y desengrase, la sedimentación primaria, la filtración, neutralización y la desorción.

La sedimentación física es el proceso mediante el cual se dejan asentar por gravedad los sólidos en suspensión en las aguas residuales. Las bacterias que crecen en este medio, junto con otros sólidos, se retiran en un tanque de sedimentación secundario y se hacen entrar de nuevo al tanque de ventilación. En este tipo de tratamiento se pueden retirar de un 60 a un $65 \%$ de los sólidos sedimentables y de 30 a $35 \%$ de los sólidos suspendidos en las aguas residuales.

Tratamientos secundarios:

Se da para eliminar desechos y sustancias que con la sedimentación no se eliminaron y para remover las demandas biológicas de oxigeno. Con estos tratamientos secundarios se pueden Expeler las partículas coloidales y similares. Puede incluir procesos biológicos y químicos. Este proceso acelera la descomposición de los contaminantes orgánicos. El procedimiento secundario más habitual es un proceso biológico en el que se facilita que bacterias aerobias digieran la materia orgánica que llevan las aguas. Este proceso se suele hacer llevando el efluente que sale del tratamiento primario a tanques en los que se mezcla con agua cargada de lodos activos (microorganismos). Estos tanques tienen sistemas de burbujeo o agitación que garantizan condiciones aerobias para el crecimiento de los microorganismos. Posteriormente se conduce este líquido a tanques cilíndricos, con sección en forma de tronco de cono, en los que se realiza la decantación de los lodos. Separados los lodos, el agua que sale contiene muchas menos impurezas. Una parte de estos lodos son devueltos al tanque para que así haya una mayor oxidación de la materia orgánica.

Se utilizan también los biodiscos que están construidos con un material plástico por el que se esparce una película de microorganismos que se regulan su espesor con el paso y el rozamiento del agua. Puede estar sumergido de un 40 a un $90 \%$ y las parte que queda en la superficie es la encargada de aportar el oxigeno a la actividad celular.

El lagunaje es utilizado en terrenos muy extensos y su duración es de 1/3 días en el proceso de retención. La agitación debe ser suficiente para mantener los lodos en suspensión excepto en la zona más inmediata a la salida del efluente. 
Revista Tecné, Episteme y Didaxis: TED. Año 2014, Número Extraordinario. ISSN Impreso: 0121-3814, ISSN web: 2323-0126

Memorias, Sexto Congreso Internacional sobre Formación de Profesores de Ciencias. 08 al 10 de octubre de 2014, Bogotá

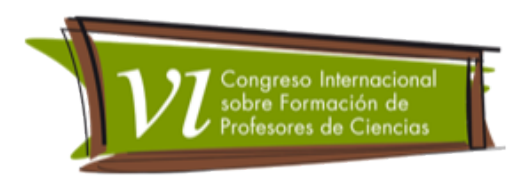

Al referirse a operaciones y procesos unitarios es porque se agrupan entre sí para constituir los tratamientos primario, secundario y terciario.

Tratamientos terciarios:

Consisten en procesos físicos y químicos especiales con los que se consigue limpiar las aguas de contaminantes concretos: fósforo, nitrógeno, minerales, metales pesados, virus, compuestos orgánicos, etc. Es un tipo de tratamiento más caro que los anteriores y se usa en casos más especiales como por ejemplo para purificar desechos de algunas industrias.

Algunas veces el tratamiento terciario se emplea para mejorar los efluentes del tratamiento biológico secundario. Se ha empleado la filtración rápida en arena para poder eliminar mejor los sólidos y nutrientes en suspensión y reducir la demanda bioquímica de oxígeno.

Una mejor posibilidad para el tratamiento terciario consiste en agregar uno o más estanques en serie a una planta de tratamiento convencional. El agregar esos estanques de "depuración" es una forma apropiada de mejorar una planta establecida de tratamiento de aguas residuales, de modo que se puedan emplear los efluentes para el riego de cultivos o zonas verdes y en acuicultura (RESIDUALES, 2010).

Algunos datos complementarios:

Se estima que el $41 \%$ de la población mundial (2600 millones de habitantes) no tiene acceso al saneamiento básico

En América Latina en el 2004, el 14\% de la población urbana (60 millones de personas) y el $51 \%$ de la población rural (65 millones de personas) carecían de sistemas de saneamiento. El 80 \% dé las aguas residuales en Colombia son arrojadas a los ríos y mares sin ningún tipo de tratamiento(Fuente: Latinosan 2007).

Propuesta de aula.

Secuencia didáctica.

La planeación y diseño del trabajo en el aula es una secuencia didáctica. Es la estructuración sistemática del trabajo en el aula en la relación estudiante, profesor, saber y entorno (relación didáctica).

La secuencia didáctica se entiende como el plan de actuación del profesor, donde se 
Revista Tecné, Episteme y Didaxis: TED. Año 2014, Número Extraordinario. ISSN Impreso: 0121-3814, ISSN web: 2323-0126

Memorias, Sexto Congreso Internacional sobre Formación de Profesores de Ciencias. 08 al 10 de octubre de 2014, Bogotá

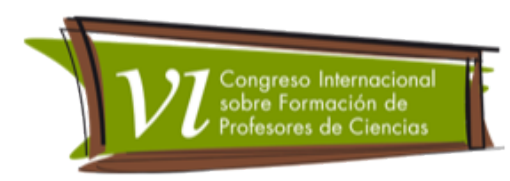

explicitan aquellos aspectos del sistema didáctico fundamentales a toda acción de enseñanza y aprendizaje.

Son pequeños ciclos de enseñanza y de aprendizaje articulados en forma de secuencia temporal y orientada a la producción de un género discursivo (explicar algún conocimiento a los compañeros, exponer un trabajo, dar una conferencia...). Pretenden den unos objetivos limitados, concretos y compartidos por los alumnos y en el proceso de planificación adquiere una especial relevancia la evaluación formativa.

Cabe señalar que...

Las secuencias didácticas contienen tres momentos básicos referidos a actividades de apertura, desarrollo y cierre.

Actividades de apertura: identifican y recuperan saberes, conocimientos previos y preconcepciones.

Actividades de desarrollo: relacionan los saberes, los conocimientos previos y las preconcepciones con el conocimiento científico.

Actividades de cierre: utilizan eficazmente los conocimientos científicos construidos durante la secuencia.

También es importante en el proceso de elaboración de las secuencias didácticas se parta de situaciones problemáticas, que están vinculadas a un tema integrador, y que consideran contenidos fácticos, procedimentales y actitudinales.

- Fácticos: se refieren a żqué conocimientos va a aprender?

- Procedimentales: se refieren a ¿̇qué va a aprender a hacer? y ¿̇cómo lo va a hacer?

- Actitudinales: se refieren a ¿̇qué va a aprender como persona? y żqué va a aprender para convivir con los demás?

Esta metodología de investigación plantea unas etapas las cuales se desarrollaran mediante el trascurso de dos meses(SEP, 2004). 
Revista Tecné, Episteme y Didaxis: TED. Año 2014, Número Extraordinario. ISSN Impreso: 0121-3814, ISSN web: 2323-0126

Memorias, Sexto Congreso Internacional sobre Formación de Profesores de Ciencias. 08 al 10 de octubre de 2014, Bogotá

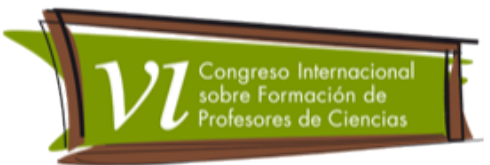

Tabla 1. Cronograma de actividades

\begin{tabular}{|c|c|c|c|}
\hline Actividad & Fecha 2014 & Objetivo & Observación \\
\hline Cartografía ambiental & $\begin{array}{l}\text { Semana del } 11 \text { al } \\
15 \text { de marzo }\end{array}$ & $\begin{array}{l}\text { Identificar las problemáticas } \\
\text { ambiental del sector y los } \\
\text { intereses de los estudiantes. } \\
\text { (ver anexo 1) }\end{array}$ & $\begin{array}{l}\text { Se establece } \\
\text { contaminación la } \\
\text { Bogotá Como la csc a } \\
\text { trabajar. }\end{array}$ \\
\hline $\begin{array}{l}\text { Identificación de la } \\
\text { población a partir de una } \\
\text { encuesta } \\
\text { demográfica }\end{array}$ & $\begin{array}{l}\text { Semana del } 1 \text { al } 5 \\
\text { de abril }\end{array}$ & $\begin{array}{l}\text { Establecer características de } \\
\text { la población (ver anexo 2) }\end{array}$ & $\begin{array}{l}\text { La población se caracteriza } \\
\text { por pertenecer a estratos } 2 \text { y } \\
3 \text { la mayoría en familias } \\
\text { estables y con niveles de } \\
\text { educación superiores ala } \\
\text { secundaria. }\end{array}$ \\
\hline $\begin{array}{l}\text { Trabajo a partir de } \\
\text { publicaciones } \\
\text { relacionadas con la } \\
\text { temática de la csc }\end{array}$ & 8-12 abril & $\begin{array}{l}\text { Identificar que se habla de } \\
\text { tema en } \\
\text { comunicativos. }\end{array}$ & $\begin{array}{lrr}\text { Se evidencian } & & \text { artículos } \\
\text { relacionados } & \text { a } & \text { la } \\
\text { conservación } & & \text { y } \\
\text { manipulación de } & \text { alimentos } \\
\text { en el matadero } & & \end{array}$ \\
\hline $\begin{array}{l}\text { Análisis y reconocimiento } \\
\text { de los sitios problema }\end{array}$ & 2-15 mayo & Reconocer el contexto & $\begin{array}{l}\text { Los estudiantes tuenen } \\
\text { contacto con el sitio } \\
\text { mencionado y observan los } \\
\text { diferentes } \\
\text { existentes }\end{array}$ \\
\hline Práctica de laboratorio & 2-15 junio & $\begin{array}{l}\text { Trabajar a partir de modelos } \\
\text { el proceso de purificación de } \\
\text { agua y su respectivo análisis } \\
\text { a partir de los diferentes } \\
\text { compuestos químicos } \\
\text { involucrados en el } \\
\text { procedimiento- }\end{array}$ & $\begin{array}{l}\text { Corroborar diferentes } \\
\text { técnicas de purificación de } \\
\text { agua en el laboratorio. }\end{array}$ \\
\hline $\begin{array}{l}\text { Discusión y análisis de las } \\
\text { causas de la csc }\end{array}$ & 2-15 junio & $\begin{array}{l}\text { Determinar las causas de la } \\
\text { problemática y posibles } \\
\text { estrategias para su solución }\end{array}$ & $\begin{array}{l}\text { El análisis de la problemática } \\
\text { sensibiliza a los estudiantes } \\
\text { los cuales muestran } \\
\text { compromiso e interés en la } \\
\text { búsqueda de soluciones o } \\
\text { alternativas que disminuyan } \\
\text { el impacto ambiental. }\end{array}$ \\
\hline $\begin{array}{l}\text { Planteamiento de nuevas } \\
\text { acciones para disminuir el } \\
\text { impacto de la csc }\end{array}$ & Julio 2014 & $\begin{array}{l}\text { Fomentar el pensamiento } \\
\text { crítico en los estudiantes. }\end{array}$ & \\
\hline $\begin{array}{l}\text { Análisis y planteamiento } \\
\text { de conclusiones y } \\
\text { posibles modificaciones } \\
\text { en la estrategia didáctica } \\
\text { aplicada. }\end{array}$ & Julio-agosto 2014 & $\begin{array}{l}\text { Realizar el trabajo final y } \\
\text { poder mostrar los resultados } \\
\text { mediante un artículo a través } \\
\text { de algún medio de } \\
\text { divulgación academico. }\end{array}$ & \\
\hline
\end{tabular}


Revista Tecné, Episteme y Didaxis: TED. Año 2014, Número Extraordinario. ISSN Impreso: 0121-3814, ISSN web: 2323-0126

Memorias, Sexto Congreso Internacional sobre Formación de Profesores de Ciencias. 08 al 10 de octubre de 2014, Bogotá

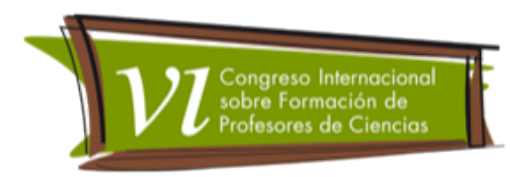

Análisis de datos: Las actividades programadas son realizadas en el presente año y el proyecto culminara en el segundo semestre del 2014 por lo tanto los análisis se encuentran en proceso de construcción de lo trabajado en el cronograma y en pro de ir adelantando la investigación se plantean las siguientes conclusiones previas.

\section{Conclusiones previas}

Los estudiantes asumen la temática de forma activa y se apoderan de la problemática siempre buscando posibles soluciones que contribuyan a reducir el impacto que la vertiente del rio Bogotá genera en la comunidad.

El enfoque CTS a partir de CSC permite establecer una coherencia entre lo que se explica en el aula de clases y lo que sucede alrededor de la misma, generando diálogos constructivos que aportan significativamente a las posibles soluciones de los problemas ambientales.

De igual forma, se pudo ver que las CSC generan conciencia en los estudiantes por las problemáticas ambientales (para este caso, la purificación del agua), y como el discurso de ellos puede aportar al cambio de la comunidad.

El fomentar la alfabetización científica a partir de CSC evidencia una trasformación en la práctica docente y en el pensamiento de los estudiantes los cuales adquieren mayor compromiso con las temáticas a trabajar en el área de ciencias naturales.

Se debe trabajar con un currículo flexible que permita involucrar la CSC sin desconocer el contenido que se deben abordar en determinado grado de educación secundaria.

\section{Referencias Bibliográficas}

Alfabetización Científica y Tecnológica Acerca de las finalidades de la enseñanza de las ciencias Gérard Fourez 1999

Papel de la educación CTS en una alfabetización, científica y tecnológica para todas las personas, José Antonio Acevedo Díaz, Ángel Vázquez Alonso y $M^{a}$ Antonia Manassero 2003 
Revista Tecné, Episteme y Didaxis: TED. Año 2014, Número Extraordinario. ISSN Impreso: 0121-3814, ISSN web: 2323-0126

Memorias, Sexto Congreso Internacional sobre Formación de Profesores de Ciencias. 08 al 10 de octubre de 2014, Bogotá

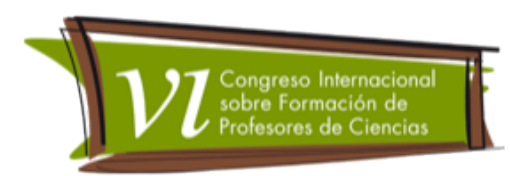

Alfabetización científica, José $M^{a}$ Sabariego del Castillo, Mercedes Manzanares GAVILÁN I congreso iberoamericano de ciencia tecnología y sociedad 2006

Educación para Todos en el 2015: ¿Alcanzaremos la meta? Resumen del informe de seguimiento de la EPT en el mundo, 2008 UNESCO, 2008. http://unesdoc.unesco.org/images/0015/001548/154820s.pdf

Martinez, L. F. (2012). questoes sociocientificas na prática docente ideologia, autonomia e formacao de professores. Sao Paulo: Fundacao Editorial Da UNESP.

Martinez, L. P. (2013). La emergencia de las cuestiones sociocientíficas en el enfoque CTSA. Góndola. Vol 8 No 1, 22-33.

Ministerio De Educación Nacional. Estándares Básicos de Competencias en Ciencias Naturales y Ciencias Sociales. Extraído 1 de noviembre de 2013 de; http://www.mineducacion.gov.co/1621/ article-87436.html.

Solbes, J. Y Vilches, A. (2004). Papel de las relaciones entre ciencia, tecnología, sociedad y ambiente en la formación ciudadana. Enseñanza de las Ciencias. Vol., 22 (3), pp. 337 -348. Extraída 1 de noviembre de 2013 de http://ensciencias.uab.es/revistes/22-3/337-48.pdf

Investugacion educativa. (2009). Recuperado el 30 de noviembre de 2012, de http://www.monografias.com/trabajos57

Residuales, T. D. (11 de 05 de 2010). http://fluidos.eia.edu.co/hidraulica/articuloses/flujoencanales/residuales/Tip os\%20de\%20Tratamiento.htm. Recuperado el 12 de 03 de 2014, de http://fluidos.eia.edu.co/hidraulica/articuloses/flujoencanales/residuales/Tip os\%20de\%20Tratamiento.htm

SEP, S. d. (2004). Subsecretaría de Educación e Investigación Tecnológicas. SEP. Recuperado el 15 de 04 de 2014, de http://www.sep.gob.mx/work/resources/LocalContent/39526/1/matematicas .pdf 
Revista Tecné, Episteme y Didaxis: TED. Año 2014, Número Extraordinario. ISSN Impreso: 0121-3814, ISSN web: 2323-0126

Memorias, Sexto Congreso Internacional sobre Formación de Profesores de Ciencias. 08 al 10 de octubre de 2014, Bogotá

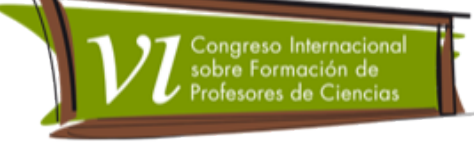

